\title{
Agenesis of Internal Carotid Artery and Ischemic Stroke, One Case Report: A Review of Literature
}

\author{
Mapaga Nyangui Jennifer, M. Martinez, P. Desbordes, A. Diawara, R. Houeze, C. Laurent, \\ J. Jacquin*
}

Department of Neurology at the DAX Hospital Center, Boulevard Yves du Manoir, Dax, France

Email: *jenica45@yahoo.fr

How to cite this paper: Jennifer, M.N., Martinez, M., Desbordes, P., Diawara, A., Houeze, R., Laurent, C. and Jacquin, J. (2018) Agenesis of Internal Carotid Artery and Ischemic Stroke, One Case Report: A Review of Literature. Open Access Library Journal, 5: e4947.

https://doi.org/10.4236/oalib.1104947

Received: September 27, 2018

Accepted: October 27, 2018

Published: October 30, 2018

Copyright $\odot 2018$ by authors and Open Access Library Inc.

This work is licensed under the Creative Commons Attribution International License (CC BY 4.0).

http://creativecommons.org/licenses/by/4.0/

\begin{abstract}
Background: Agenesis of the internal carotid artery (ICA) is a rare anatomic variation of the cerebral circulation. A malfunction during the embryonic period is at stake. It is very often asymptomatic and therefore discovered incidentally. Association with ischemic stroke is exceptional. Physiopathology is uncertain; the hypothesis of a blood flow reversal is reported in the literature. The diagnosis is based on the absence of a carotid canal as revealed by CT scans at skull base level with bone settings. Other non-invasive techniques, including echo-Doppler of the neck vessels, can now make the diagnosis. Objective: Discuss the association between occurrence of an ischemic stroke in the left posterior sylvian territory and discovery of ipsilateral carotid agenesis. Case report: A 24-year-old female patient was prospectively recruited at DAX hospital center (France). Vascular risk factors involved active smoking of 8 pack-years and a combined estrogen/progestin contraceptive. Her family history included an uncle with heterozygote Factor V Leiden mutation. She presented a left upper limb sensorimotor deficit. Nuclear Magnetic Resonance Angiography (MRA) revealed a right superficial sylvian ischemic stroke associated with agenesis of the right internal carotid artery. CT scan at skull base level with bone settings showed absence of a right carotid canal, thus confirming agenesis. An opinion was then requested for an arteriography which showed an operative polygon of Willis, a sylvian artery or middle cerebral artery (MCA) irrigated by a very large right posterior communicating artery (PCOM) and the left anterior cerebral artery (ACA) supplied by the anterior communicating artery (ACOM), through the left carotid system. The right sylvian territory where stroke occurred was therefore supplied by the functional vertebrobasilar system. ECG and four-day meticulous monitoring detected no cardiac rhythm disorders. Transesophageal echocardio-
\end{abstract}


graphy was normal. Blood tests results showed normal blood coagulation with glycohemoglobin level at $4.6 \%$. Total cholesterol was $1.42 \mathrm{~g} / \mathrm{l}$ including LDL-C at $0.82 \mathrm{~g} / \mathrm{l}$ and HDL-C at $0.36 \mathrm{~g} / \mathrm{l}$; triglycerides levels were $1.23 \mathrm{~g} / \mathrm{l}$. VDRL-TPHA serodiagnosis for syphilis, and HIV serology were all negative. Thrombophilia testing was performed and showed absence of Factor V Leiden mutation. Homocysteinemia level was normal. The patient was discharged under KARDEGIC $160 \mathrm{mg}$, one daily with home rehabilitation. Currently she's doing well and no recurrence is observed.

\section{Subject Areas}

Clinical Trials

\section{Keywords}

Right Internal Carotid Artery Agenesis, Ischemic Stroke, Rare

\section{Introduction}

Right internal carotid artery agenesis (ICA) is a developmental anomaly by the $24 \mathrm{~mm}$ embryonal stage [1] [2]. It is consistent with interrupted embryonic development of the ICA associated with absence of the ipsilateral carotid canal [3]. Agenesis of the ICA is usually asymptomatic, and therefore, discovered accidently. Diagnosis is based on the absence of a carotid canal. Through angiography, in absence of blood flow, the differential diagnosis includes artery occlusion, hypoplasia or aplasia. Absence of carotid canal confirms the diagnosis of agenesis. Symptoms may be related to cerebrovascular insufficiency, to compensatory dilatation of intracranial vessels, or to aneurysm. Ischemic stroke is scarcely described in the literature. Its physiopathology is based on hypotheses. We discuss the association between occurrence of ischemic stroke and congenital anomaly that was previously unknown.

\section{Case Report}

We report the case of a 24 years old female patient with vascular risk factors such as active smoking of 8 pack-years and a combined estrogen/progestin contraceptive. Her family history included an uncle with heterozygote factor V Leyden mutation. Presenting symptoms included a general feeling of being unwell without loss of consciousness, a mild dysarthria event and a fast-regressive left hemiparesis, with persistent weakness particularly in the left hand. Note that she had no headache. She was immediately admitted to the emergency department for thrombolysis. Brain scan and computed tomography (CT) Angiography of supra-aortic trunks completed with Magnetic Resonance Angiography (MRA) revealed ischemic stroke in the right sylvian territory affecting the parietal lobe, with no hemorrhagic conversion and no arterial occlusion [Figure 1]. Alternatively, magnetic resonance imaging (MRI) showed a vascular anatomic variant 
such as agenesis of the right internal carotid artery (ICA) with the right middle cerebral artery (MCA) fed through a dilated posterior communicating artery (PCOM) arising from the basilar artery [Figure 2; Figure 3]. CT scans at skull base level with bone settings showed absence of the right carotid canal, thus confirming agenesis, for which arteriography was requested [Figure 4]. Arteriography showed an operative circle of Willis, a MCA supplied by an enlarged right

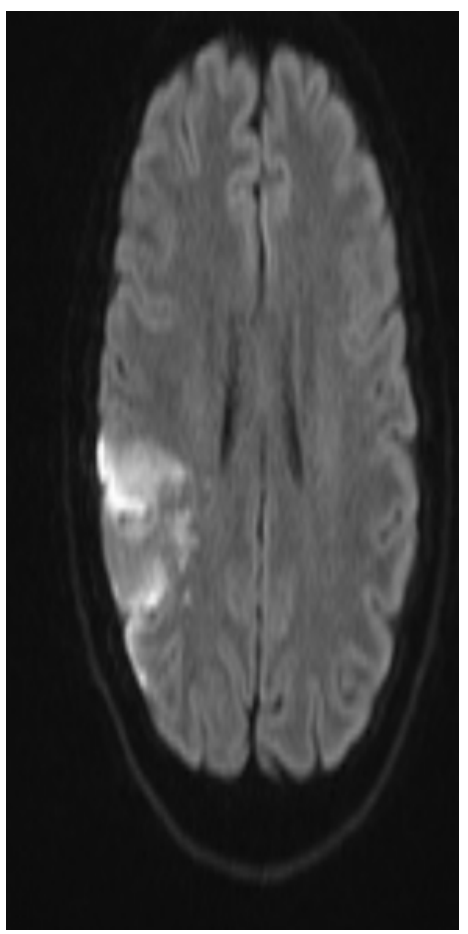

Figure 1. Right Sylvian ischemic stroke. MRI of 24-year-old female patient (DAX hospital center).

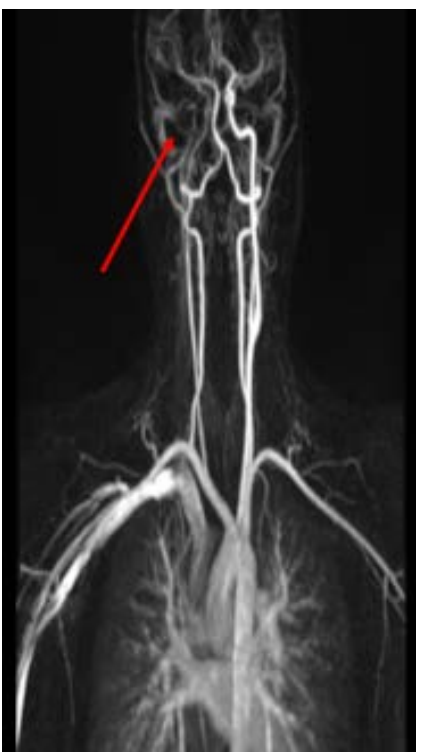

Figure 2. Agenesis of the right internal carotid artery. MRI angiography of 24-year-old female patient (DAX hospital center). 


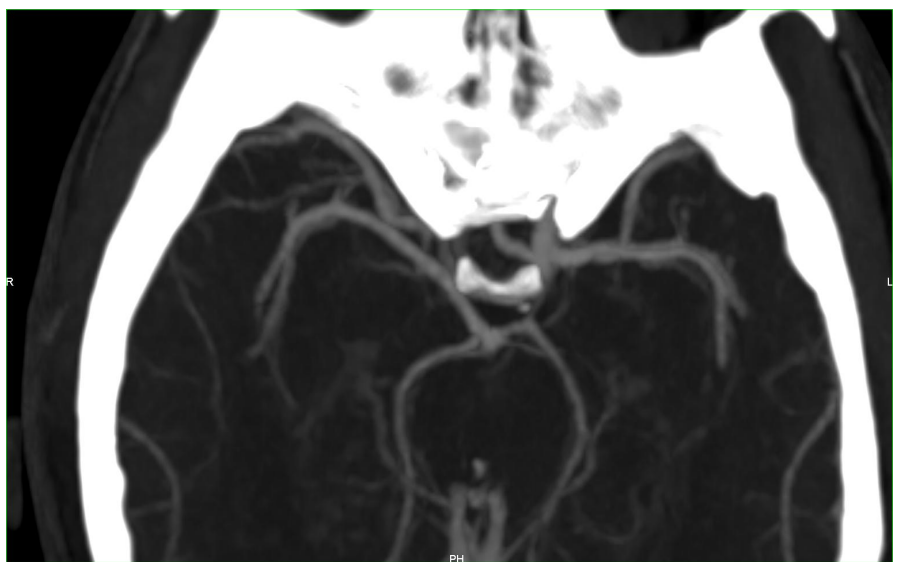

Figure 3. Right MCA fed through dilated posterior communicating artery arising from the basilar artery. MRI angiography of 24-year-old female patient (DAX hospital center).

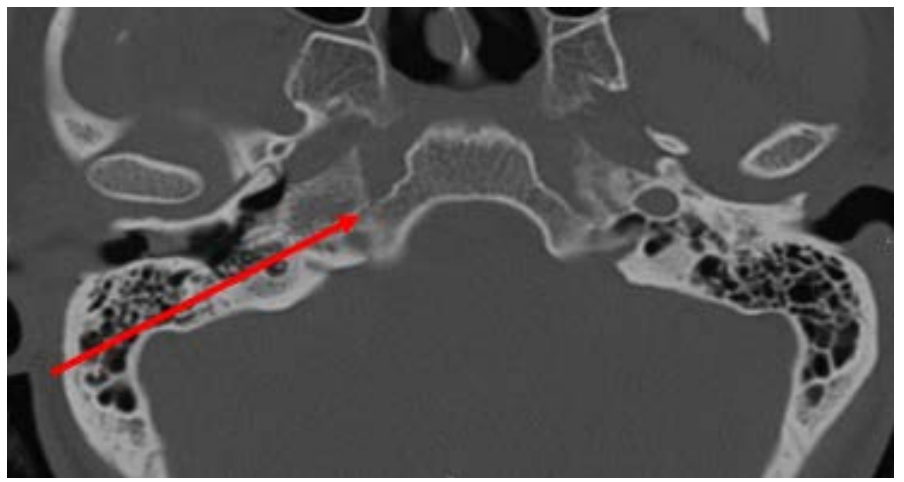

Figure 4. CT scan of the skull base shows the absence of the right carotid canal. 24-year-old female patient (DAX hospital center).

PCOM and left anterior cerebral arteria (ACA) supplied by anterior communicating artery (ACOM) through the left carotid circulation. The right sylvian territory where stroke occurred was thus supplied through the functional vertebrobasilar circulation. This agenesis doesn't explain cerebral ischemic stroke. ECG and four-day meticulous monitoring detected no cardiac rhythm disorders. Through transesophageal echocardiography, left ventricle size and kinetic were normal, no valvular pathology was detected, left atrium and auricle were echo-free spaces without thrombus, left auricle emptying was normal, as well as interatrial septum kinetic which was impervious to microcavitation, no atheromatous plaque were detected in the descending thoracic aorta, and no ulceration either. Blood tests results included glycohemoglobin level of $4.6 \%$, total cholesterol level at $1.42 \mathrm{~g} / \mathrm{l}$, with LDL-C of $0.82 \mathrm{~g} / \mathrm{l}$ and HDL-C of $0.36 \mathrm{~g} / \mathrm{l}$, triglyceride levels at $1.23 \mathrm{~g} / \mathrm{l}$. VDRL and TPHA serological test for syphilis, and HIV serology were all negative. Thrombophilia testing was performed and showed absence of Factor V Leiden mutation. Homocysteinemia level was normal. Management included prevention of vascular risk factors such as smoking cessation, stopping estrogen-progestogens. The patient was put on KARDEGIC antiaggregant platelets, $160 \mathrm{mg}, 1$ per day and functional rehabilitation at home. She has been out 
for 6 months and no recurrence has been observed, she is monitored every 3 months.

\section{Discussion}

Agenesis of ICA is a very rare developmental anomaly with less than 200 cases reported in the literature [4]. It was described for the first time by Tode in 1787 and identified on post-mortem examination [5]. In 1954, the first case of ICA agenesis at cerebral angiography was reported by Verbiest [6]. Agenesis is some form of dysgenesis, like hypoplasia and aplasia according to Lie Classification; they are secondary to abnormality in embryonic development [7]. Mechanical and hemodynamic stresses over the embryo included exaggerated folding of embryo toward one side and constriction by amniotic band have been hypothesized for unilateral agenesis [8]. As yet, there is no explanation for bilateral agenesis [9]. ICA agenesis, aplasia and hypoplasia occur in about less than $0.01 \%$ of the population [10]. Lie and Hage have defined carotid agenesis as complete failure of ICA to develop, hypoplasia as incomplete development of the organ with diffuse luminal narrowing of the internal artery, and aplasia as arrested development of the organ. Therefore, in agenesis the bony carotid canal is absent, whereas in aplasia and hypoplasia the bony carotid canal is present [4] [7]. From the embryological perspective, common carotid artery (CCA) and proximal portion of ICA originate from the third aortic arch which develops as early as 4 weeks gestation, whereas the cranial base starts to develop after 5 weeks gestation. The dorsal aortae segments contribute in formation of the CCA. [11] [12]. The carotid canal only develops if there is an internal carotid artery [13]. The branchial arches are found along the heart protrusion, some of them regress and others involute into arteries. The first branchial arch regresses by day 31 and a remnant of it forms part of the maxillary artery (IMA); the second branchial arch gives rise to the stapedial and hyoid arteries. The development of the fourth arch is different for the right and left sides. On the left side arch IV persists as the arch of the aorta, which grows significantly and is continuous with the primitive left dorsal aorta. The left subclavian artery arises directly from the aorta. On the right side, arch IV contributes to the proximal portion of the right subclavian artery and arch VI gives rise to the pulmonary artery [14]. Agenesis can be classified as complete or partial but was also defined by Lasjaunias based on embryological description. Complete agenesis of ICA results in complete absence of ICA and the carotid bony canal. Female predominance has been seen, as in the present reported case, but most likely on the left side [15]. The MCA got supply from post communication artery (PCOM) and the anterior cerebral artery (ACA) from an hypertrophic anterior communicating artery (ACom). The single precommunicant segment (A1 segment of Fisher classification) of ACA ipsilateral to the anomaly is usually hypoplastic [16]. More anatomical variants may be associated, like the presence of an accessory MCA, or Infraoptic course of the precommunicant segment of the ACA, or the ophthalmic artery emerging 
from the MCA or the meningeal artery [12]. Partial agenesis can affect all the segments of the ICA with predilection for the cervical segment. This anomaly, when unilateral, may be left or right-sided and male predominant [17]. Absence of cervical segment of ICA is defined by the existence of a particular supplying system via a prominent intercarotid artery filling the carotid siphon and all the other branches, except ACA. Anastomosis can be either intrasellar, intra or retroclival [17] [18] [19]. Other anomalies are frequent such as hypoplasia of the precommunicant segment of ipsilateral ACA, or ACOM aneurysm.

Based on the embryology of ICA, P. Lasjaunias and A. Santoyo-Vazquez showed that ICA comprises six segments, i.e. cervical, petrous, vertical cavernous, horizontal cavernous, clinoid and cisternal segments. Each of these segments displays a specific course and limits, defined by the origin of the following embryonic arteries: ventral pharyngeal hyoid, mandibular, primitive maxillary, trigeminal, dorsal ophthalmic and ventral ophthalmic. Each segment is independent and may show agenesis. In such cases the internal carotid blood flow is rerouted to afford usual ICA supply distal to the agenetic segment. Thus, various segmental agenesis have been described: cervical, petrous, cavernous. Differentiation can be made between congenital versus acquired absence of the ICA, thus allowing the clinician to identify normal, sometimes overlooked, predictable, well documented, albeit rare variations, rather than to mistake them for a pathological condition [20]. Reports have shown that dysgenesis of the left internal carotid is 3 times more frequent than right dysgenesis, and bilateral ICA agenesis or hypoplasia are more exceptional [10] [21]. Most patients with ICA dysgenesis are asymptomatic due to the development of arterial collateral supply to the cerebral circulation [3]. In type A, unilateral absence of the ICA is associated with collateral circulation to the ipsilateral ACA through a patent ACOM and to the ipsilateral MCA from the posterior circulation via the PCOM. In type B, the ACA and MCA ipsilateral to the anomaly are supplied across a patent ACOM. Type C represents bilateral agenesis of the ICA with supply to the ACA and MCA from the posterior circulation via the PCOM. Type D represents unilateral agenesis of the cervical segment of the ICA with reconstitution of cavernous communication through an anastomotic carotid siphon from the contralateral cavernous segment of ICA. Type $\mathrm{E}$ is a unique type with diminutive ACAs supplied by bilateral hypoplastic ICAs instead of complete absence. Caliber of PCOM is enlarged whereas MCA's one is normal, suggesting the majority of blood flow in MCA is supplied by posterior circulation. Carotid hypoplasia is a more appropriate term for type $\mathrm{E}$, as the carotid canal persists, with remnants of small vessels. Type F cases show collateral flow to the distal ICA via anastomoses from distal branches of the external carotid artery (ECA) system. Since Lie's original classification, Tatsuaki Hattori and al in 1998 have described another type of collateral flow to ICA and MCA via a persistent trigeminal artery (PTA) [22].

Usually, internal carotid artery agenesis is discovered incidentally and many 
patients are asymptomatic due to robust collateral circulation, but they may present with recurrent headache, blurring vision, hearing loss, hemiparesis with facial nerve palsy or not, ipsilateral Horner's syndrome associated with cerebral ischemia or intracranial hemorrhage due to ruptured aneurysms [3] [23]. Transient neurologic signs associated with transient ischemic attack have also been reported in the literature.

In 2011, Olga Kiritsi's study suggested transient ischemic attack (TIA) was associated with cerebrovascular haemodynamics (hypotension). There was no consistent association between TIA and carotid agenesis, due to sufficient collateral circulation [3]. A similar case, as reported in this study, related acute ischemic vascular attack to agenesis of ICA. Aysegul Sagir Kahraman and al in 2016 reported the case of a 27-year-old patient, with unremarkable medical history, presenting with headache, dizziness, left hand paresis. Thalamic and subthalamic ischemic stroke related to agenesis of ICA was detected through imagery. They reported that cerebral stroke may be related to vascular insufficiency or collaterals changing flow pattern [24]. The same explanation may apply to the present case of cerebral stroke. The patient's vascular risk factors (smoking, estrogen/progestin contraceptives) may give further arguments. Oral contraceptive is described to increase the risk of cerebral stroke even at low dose, the relative risk being 2,9 $\left(\mathrm{CI}_{95 \%}=[1.3-6.7]\right)$ and even 5 for female smokers [25] [26]. In addition to the collaterals changing flow pattern, a second hypothesis for the reported stroke involves impaired cerebral autoregulation in the PCOM from the vertebrobasilar system. This low autoregulation, as described in the literature accounts for the preferential location of posterior reversible encephalopathy syndromes [26]. Cerebral stroke is a very rare complication, whereas, the incidence of intracranial aneurysms has been reported as $25 \%-34 \%$ as compared to the $1 \%-5 \%$ seen in general population [8] [27]. Increased blood flow through collaterals and altered flow dynamics are plausible explanations [2] [28]. Other abnormalities such as corpus callosum agenesis, neurofibromatosis, meningocele, aortic coarctation, cardiac anomalies [23] [29] and Goldenhar syndrome [27] may be associated with agenesis of the ICA [23] [29]. Angiography only cannot differentiate agenesis and aplasia [30]. In case of ICA dysgenesis, computed tomography (CT) is the ideal imaging modality to prove absence of carotid canal (agenesis), or underdevelopment (aplasia and hypoplasia) of the contralateral canal. Such suspected malformation is easily evaluated with accuracy by the supra-aortic trunk echo-Doppler, completed with transcranial Doppler ultrasound (TCD), as first-line reliable examinations. They provide measurement of suggestive morpho-hemodynamic characteristics of cervical vessels as well as blood flow velocity through the cranial windows. Unlike arteriography, Doppler test can help discriminate agenesis from aplasia, or assess the differential diagnosis of suspected occlusion (atheroma, embolism, dissection) [31]. No treatment is required or even possible for congenital and asymptomatic carotid agenesis, but potential complications may occur later in life, especially in case of 
atheromatous progression [1] [8].

\section{Conclusion}

Congenital agenesis of the ICA is a rare vascular malformation, usually asymptomatic due to sufficient collaterals development. But the constraints imposed on the collateral circulation may lead to potential complications, like ischemic stroke. This anomaly should not be overlooked. Diagnosis is made by CT scans at skull base level with bone settings, showing absence of the carotid canal.

\section{Conflicts of Interest}

The authors declare that they have no competing interests.

\section{References}

[1] Padget, D.H. (1948) The Development of the Cranial Arteries in the Human Embryo. Contrib Embryol, 32, 205-261.

[2] Okawa, M., Higashi, T., Komiyama, M., Fukuda, K., Abe, H. and Inoue, T. (2015) Left Internal Carotid Artery Agenesis with Trans-Sellar Collateral and a Right Aortic Arch: Case Report. Interventional Neuroradiology, 21, 759-764. https://doi.org/10.1177/1591019915609130

[3] Kiritsi, O., Noussios, G., Tsitas, K. and Lappas, D. (2012) Unilateral Agenesis of the Internal Carotid Artery Presented as Transient Ischaemic Attack: A Case Report. Surgical and Radiologic Anatomy, 34, 475-477. https://doi.org/10.1007/s00276-011-0901-Z

[4] Li, S., Hooda, K., Gupta, N. and Kumar, Y. (2017) Internal Carotid Artery Agenesis: A Case Report and Review of Literature. The Neuroradiology Journal, 30, 186-191. https://doi.org/10.1177/1971400917692162

[5] Tode. Medizinisch chirurgische Bibliothek (Kopenhgen) 1787; 10: 408. In: Die, K.W., der Arterien, V. und Venen, H.J., Eds., Handbuch der System Anatomie des Menschen, Vol. 3, Part 1, 2nd Edition, Vieweg, Brunswick, 1876.

[6] Claros, P., Bandos, R., Gilea, I., et al. (1999) Case Report: Major Con-Genital Anomalies of the Internal Carotid Artery-Agenesis, Aplasia, and Hypoplasia. International Journal of Pediatric Otorhinolaryngology, 49, 69-76. https://doi.org/10.1016/S0165-5876(99)00012-9

[7] Lie, T. and Hage, J. (1968) Congenital Anomalies of the Carotid Arteries. Plastic and Reconstructive Surgery, 42, 283. https://doi.org/10.1097/00006534-196809000-00046

[8] Sarcelle, J.S., Naheedy, M.H. and Hasso, A.N. (1980) Agénésie totale de l'artère carotide interne. AJNR American Journal of Neuroradiology, 1, 435-442.

[9] Hattori, T., Kobayashi, H., Inoue, S. and Sakai, N. (1998) Persistent Primitive Trigeminal Artery Associated with Absence of Internal Carotid Artery. Surgical Neurology, 50, 352-355. https://doi.org/10.1016/S0090-3019(97)00491-6

[10] Given, C.A. II, Huang-Hellinger, F., Baker, M.D., et al. (2001) Congenital Absence of the Internal Carotid Artery: Case Reports and Review of the Collateral Circulation. American Journal of Neuroradiology, 22, 1953-1959.

[11] Chawaf, A.R. (1970) Les artères carotides primitives. Développement et variations. Mémoires du Labo Anat Fac Méd, Paris, ${ }^{\circ} 16$. 
[12] David, H., Dubayle, P., Girodeau, A., Sarrazin, J.L. and Boyer, B. (2000) Agénésie de la carotid interne à propos d'un cas. Journal de radiologie, 82, 147-150.

[13] Teal, J.S., Naheedy, M.H. and Hasso, A.N. (1980) Total Agenesis of the Internal Carotid Artery. Am J Neuroradiol, 1, 435-449.

[14] Mellal, A. (2010) Application pratique de l'anatomie humaine. Tome 1, Viscères du tronc. Vol. 1, Publibook, Paris, 255 p.

[15] Handa, J., Matsuda, I., Nakasu, S. and Nakano, Y. (1980) Agenesis of the Internal Carotid Artey: Angiographic, Tomographic and Computed Tomographic Correlation. Neuroradiology, 19, 207-211. https://doi.org/10.1007/BF00376709

[16] Fisher, E. (1938) Die Lageabweichungen der vorderen Hirnartie im gefaßbild. Zentralblatt für Neurochirurgie, 3, 300-313.

[17] Pascaud, J.L., Vigneu, P., Hummel, P., Bouchet, J.B., Rihollet, J. and Pascaud-Ged, E. (1982) Absence partielle de carotide interne avec anastomose intercarotidienne transsellaire. Nouvelle observation et revue de la littérature. Journal of Radiology, 63, 37-40.

[18] Elefante, R., Fucci, G., Granata, F., Graziussi, G. and Smaltino, F. (1983) Agenesis of the Right Internal Carotid Artery with an Unusual Transsellar Intracavernous Intercarotid Connection. American Journal of Neuroradiology, 4, 88-89.

[19] Faivre, J., Vallée, B., Carsin, M., Scarabin, J.M. and Simon, J. (1978) Agénésie des portions cervicale et pétreuse de la carotide interne gauche. Revascularisation de sa portion caverneuse par une anastomose intercarotidienne transsphénoidale. Journal of Neuroradiology, 5, 133-138.

[20] Lasjaunias, P. and Santoyo-Vazquez, A. (1984) Agenesis of the Internal Carotid Artery: Angiographic Aspects with Embryological Discussion. Clinical Anatomy, 6, 133-141. https://doi.org/10.1007/BF01773165

[21] Tasar, M., Yetiser, S., Tasar, A., et al. (2004) Congenital Absence or Hypoplasia of the Carotid Artery: Radioclinical Issues. American Journal of Otolaryngology, 25, 339-349. https://doi.org/10.1016/j.amjoto.2004.04.008

[22] Hattori, T., Kobayashi, H., Inoue, S. and Sakai, N. (1998) Persistent Primitive Trigeminal Artery Associated with Absence of Internal Carotid Artery. Surgical Neurology, 50, 352-355. https://doi.org/10.1016/S0090-3019(97)00491-6

[23] Florio, F., Balzano, S., Nardella, M., et al. (1999) Congenital Absence of the Internal Carotid Artery. Cardio Vascular and Interventional Radiology, 22, 74-78. https://doi.org/10.1007/s002709900334

[24] Kahraman, A.S., Kahraman, B., Ozdemir, Z.M., Dogan, M., Kaya, M., Gormeli, C.A. and Durak, M.A. (2016) Congenital Agenesis of Right Internal Carotid Artery: A Report of Two Cases. Journal of the Belgian Society of Radiology, 100, 48.

[25] Leys, D., Lucas, C., Gautier, C., Hachulla, E. and PruvoLes, J.-P. (2004) Accidents is chémiques cérébraux du sujet jeune. Mini-revueSang Thrombose Vaisseaux, 16, 43-50.

[26] Zunker, P., Happe, S., Geordadis, A.L., Louwen, F., Georgiadis, D., Ringelstein, E.B., et al. (2000) Maternal Cerebral Hemodynamics in Pregnancy-Related Hypertension. A Prospective Transcranial Doppler Study. Ultrasound in Obstetrics \& Gynecology, 16, 179-187.

[27] Ottaviano, G., Calzolari, F. and Martini, A. (2007) Goldenhar Syndrome in Association with Agenesia of the Internal Carotid Artery. International Journal of Pediatric Otorhinolaryngology, 71, 509-512.

https://doi.org/10.1016/j.ijporl.2006.11.003 
[28] Afifi, A.K., Godersky, J.C., Menezes, A., Smoker, W.R. and Bell, W.E. (1987) Cerebral Hemiatrophy, Hypoplasia of Internal Carotid Artery, and Intracranial Aneurysm. A Rare Association Occurring in an Infant. Archives of Neurology, 44, 232-235.

[29] Xie, T., Zhang, X.B., Li, Q.P., et al. (2010) Hemifacial Spasm Patient with Ipsilateral Total Absence of Common Carotid Artery, Vertebra-Lartery and Aneurysm of the Contralateral Internal Carotid Artery. Surgical and Radiologic Anatomy, 32, 707-710. https://doi.org/10.1007/s00276-010-0660-2

[30] Lie, T.A. (1968) Anomalies congénitales des artères carotides. Excerpta Medica, Amsterdam, 35-51.

[31] Fumagalli, G. (1999) Arpaia Diagnostic Non Invasif d'une agénésie de la carotide interne. Journal d’ Echographie et de Médecine par Ultrasons, 20, 233. 